\title{
Review
}

Cardiovascular Risk/Epidemiology

Diabetes Metab J 2021;45:158-172

https://doi.org/10.4093/dmj.2020.0296

pISSN 2233-6079 • eISSN 2233-6087

DIABET\&S \& METABOLISM JOURNAL

\section{Diabetes Management in Patients with Heart Failure}

\author{
Jia Shen, Barry H. Greenberg \\ Division of Cardiology, Department of Medicine, University of California San Diego, La Jolla, CA, USA
}

Diabetes and heart failure (HF) are common diseases, each affecting large segments of the world population. Moreover, prevalence rates for both are expected to rise dramatically over coming decades. The high prevalence rates of both diseases and wellrecognized association of diabetes as a risk factor for HF make it inevitable that both diseases co-exist in a large number of patients, complicating their management and increasing the risk of a poor outcome. Management of diabetes has been shown to impact clinical events in patients with HF and there is emerging evidence that agents used to treat diabetes can reduce HF events, even in non-diabetic patients. In this review we summarize the clinical course and treatment of patients with type 2 diabetes mellitus (T2DM) and HF and review the efficacy and safety of pharmacological agents in patients with T2DM at risk for HF and those with established disease.

Keywords: Diabetes mellitus; Heart failure; Risk factors; Sodium glucose cotransporter 2 inhibitor

\section{INTRODUCTION}

There are over 463 million people afflicted with diabetes mellitus (DM) worldwide [1], whereas over 26 million have heart failure (HF) [2]. The prevalence of both diseases are expected to increase over time. While each condition is individually associated with considerable morbidity and mortality, they often occur together, complicating management, adversely affecting patient outcomes, and increasing cost of care. The prevalence of diabetes in patients with HF ranges from $25 \%$ to $45 \%$ and is higher in hospitalized patients (Table 1) [3-17]. Diabetes contributes to disease progression in $\mathrm{HF}$ and is associated with worse prognosis, even when guideline recommended HF therapies are utilized [6,7]. The relationship between hyperglycemia and cardiovascular (CV) outcomes in patients with diabetes and HF is complex. Data from outcomes trials indicate that HF is a critical outcome in patients with DM and suggest that glucose-lowering medications may influence the risk of HF development and progression. The intensity of, and specific pharmacologic agent chosen for glycemic control in patients with type 2 diabetes mellitus (T2DM) are critical components of HF management. This review will summarize contemporary data on the outcomes, efficacy, and safety of pharmacological agents in patients with T2DM at risk for HF and those with established disease.

\section{IMPACT OF DIABETES ON HEART FAILURE OUTCOMES}

Approximately 25\% of HF patients overall and $40 \%$ of hospitalized HF patients have DM $[3,4,18]$. The presence of DM in HF patients is associated with an increased risk of death, hospitalization, and prolonged hospital stay [19,20]. In the Effect of Candesartan for the Management of Patients with Chronic Heart Failure (CHARM) program DM was present in $28.4 \%$ of patients and was associated with increased risk of CV death or HF hospitalization in patients with both heart failure with preserved ejection fraction (HFpEF) (hazard ratio [HR], 2.0; 95\% confidence interval [CI], 1.70 to 2.36 ) and heart failure with reduced ejection fraction (HFrEF) (HR, 1.60; 95\% CI, 1.44 to
Corresponding author: Barry H. Greenberg (D) https://orcid.org/0000-0002-66059385

Division of Cardiology, Department of Medicine, UC San Diego Health Cardiovascular Institute, 9452 Medical Center Drive, La Jolla, CA 92037-7411, USA

E-mail: bgreenberg@ucsd.edu
This is an Open Access article distributed under the terms of the Creative Commons Attribution Non-Commercial License (https://creativecommons.org/licenses/by-nc/4.0/) which permits unrestricted non-commercial use, distribution, and reproduction in any medium, provided the original work is properly cited.

Copyright (C) 2021 Korean Diabetes Association 
Table 1. Prevalence of diabetes in patients with heart failure in the general population and in selected trials of heart failure

\begin{tabular}{lcc}
\hline Country/Clinical Trial & Number & $\begin{array}{c}\text { Prevalence of } \\
\text { diabetes in } \\
\text { heart failure } \\
\text { patients, \% }\end{array}$ \\
\hline Country & \\
USA, Olmsted County [9] & 25.0 \\
Europe, EuroHeart Failure Survey [10] & & 27.0 \\
England, Heart of England Study [11] & & 24.0 \\
Italy [12] & & 30.0 \\
China, Shanghai [13] & & 29.1 \\
Korea, National Sample Cohort [5] & & 49.1 \\
Japan, CHART Cohort Study [14] & & 47.4 \\
Clinical trial & & \\
SOLVD [3] & 2,569 & 25.8 \\
MERIT-HF [15] & 3,991 & 24.5 \\
CHARM-Alternative [7] & 2,028 & 27.0 \\
SHIFT [16] & 6,558 & 30.4 \\
EMPHASIS-HF [4] & 2,737 & 31.4 \\
PARADIGM-HF [6] & 8,442 & 34.7 \\
OPTIME (hospitalized) [17] & 949 & 44.2 \\
DAPA-HF [8] & 4,744 & 45.0 \\
\hline
\end{tabular}

CHART, Chronic Heart Failure Analysis and Registry in the Tohoku District; SOLVD, Effect of Enalapril on Survival in Patients with Reduced Left Ventricular Ejection Fractions and Congestive Heart Failure; MERIT-HF, Metoprolol CR/XL Randomized Intervention Trial in Congestive Heart Failure; CHARM, Effect of Candesartan for the Management of Patients with Chronic Heart Failure; SHIFT, Systolic Heart Failure Treatment with the If Inhibitor Ivabradine Trial; EMPHASIS-HF, Eplerenone in Patients with Systolic Heart Failure and Mild Symptoms; PARADIGM-HF, Prospective comparison of ARNI with ACEI to Determine Impact on Global Mortality and morbidity in Heart Failure; OPTIME, Outcomes of a Prospective Trial of Intravenous Milrinone for Exacerbations of Chronic Heart Failure; DAPAHF, Dapagliflozin in Patients with Heart Failure and Reduced Ejection Fraction.

1.77) [21]. For all-cause mortality, the adjusted risk conferred by DM was similar in both HFrEF (adjusted hazard ratio [aHR], 1.55; 95\% CI, 1.38 to 1.74) and HFpEF (aHR, 1.84; 95\% CI, 1.51 to 2.26 ) groups [21].

The European Society of Cardiology (ESC) and Heart Failure Association (HFA) Long-Term Registry, a multinational cohort of 9,428 outpatients with HF compared outcomes between patients with and without DM. Overall, those with DM (36.5\%) had higher cumulative rates of 1-year all-cause death
(HR, 1.28; 95\% CI, 1.07 to 1.54), CV death (HR, 1.28; 95\% CI, 0.99 to 1.66 ), and HF hospitalization (HR, 1.37; 95\% CI, 1.17 to 1.60) [22]. There was a significant and independent association between increasing glycosylated hemoglobin (HbA1c) levels and risk of 1-year survival outcomes [22]. Finally, in a large meta-analysis of 381,725 patients with acute and chronic HF over a median follow-up of 3 years, DM was associated with a higher risk of all-cause death (HR, 1.28; 95\% CI, 1.21 to 1.35), CV death (HR, 1.34; 95\% CI, 1.20 to 1.49), and hospitalization (HR, 1.35; 95\% CI, 1.20 to 1.50) [23]. The impact of $\mathrm{DM}$ on mortality and hospitalization was greater in patients with chronic as opposed to acute HF [23].

\section{MANAGEMENT OF DIABETES IN HEART FAILURE PATIENTS}

\section{Target glycemic control in HF patients}

Numerous clinical trials have evaluated the relationship between tight glycemic control and CV end points. While intensive glycemic treatment to achieve low HbAlc targets reduced the long-term risk of microvascular complications (retinopathy, nephropathy, and peripheral neuropathy), it has not been shown to significantly reduce the risk of major adverse CV events [24-27]. Prospective, randomized controlled trials addressing the optimal glycemic targets in HF patients with DM have not been performed. Four large trials that studied the effect of intensive glucose lowering on CV risk enrolled few patients with HF and HF hospitalization was not a primary end point [28-31].

In contrast to epidemiologic evidence demonstrating a linear relationship between elevated $\mathrm{HbAlc}$ levels and worse CV outcomes in subjects free of HF at baseline [32], the relationship between $\mathrm{HbAlc}$ and outcomes appears more complex in patients with HF [33]. Several studies have demonstrated a Ushaped relationship between $\mathrm{HbAlc}$ and mortality, with the lowest risk in patients with $\mathrm{HbAlc} 7 \%$ to $8 \%$ [33-36]. A metaanalysis of 37,229 patients followed from 2.3 to 10.1 years found that compared to regular glycemic control, intensive glycemic control in patients with T2DM did not significantly reduce the occurrence of HF events (odds ratio [OR], 1.20; $95 \% \mathrm{CI}, 0.96$ to 1.48 ) while intensive glycemic control with thiazolidinediones (TZDs) increased the risk of HF (OR, 1.33; $95 \%$ CI, 1.02 to 1.72 ) [37].

Current guidelines recommend an $\mathrm{HbAlc}$ goal of $<7 \%$ for most adults but allow for individualization based on patient 
characteristics and comorbid conditions [38]. A higher goal of $<8.0 \%$ is recommended for older patients, those with limited

Table 2. American Diabetes Association glycemic targets in adults [38]

\begin{tabular}{cl}
$\begin{array}{c}\text { HbA1c } \\
\text { goal }\end{array}$ & \multicolumn{1}{c}{ Patient population } \\
\hline$<7.0 \%$ & Majority of non-pregnant adults \\
$<6.5 \%$ & $\begin{array}{c}\text { Minority of adults without significant comorbid conditions } \\
\text { that can be safely achieved without significant hypoglyce- } \\
\text { mic or other adverse effects of treatment. }\end{array}$ \\
$<8.0 \%$ & $\begin{array}{c}\text { Adults with history of severe hypoglycemia, limited life ex- } \\
\text { pectancy, advanced microvascular or macrovascular } \\
\text { complications, extensive comorbid conditions, or long- } \\
\text { standing diabetes in whom the goal is difficult to achieve } \\
\text { despite diabetes self-management education, appropriate } \\
\text { glucose monitoring, and effective doses of multiple glu- } \\
\text { cose-lowering agents including insulin. }\end{array}$ \\
\hline
\end{tabular}

HbA1c, glycosylated hemoglobin. life expectancy, advanced macrovascular complications, or extensive comorbid conditions (Table 2) [38].

\section{Choice of glucose lowering agents in patients with $\mathrm{HF}$ or at high risk for developing $\mathrm{HF}$}

This section reviews data on the glucose-lowering medications by class. CV outcomes of trials of glucagon-like peptide-1 (GLP-1) receptor agonists, dipeptidyl peptidase-IV (DPP-4) inhibitors, sodium-glucose cotransporter 2 (SGLT2) inhibitors are summarized in Tables 3-5.

\section{Metformin}

Metformin is the preferred initial pharmacologic agent for treating T2DM [39]. Once initiated, metformin should be continued as long as it is tolerated and not contraindicated; other agents are added to metformin as needed [39]. Metformin decreases hepatic glucose production and intestinal absorption of glucose, while improving insulin sensitivity by increasing

Table 3. Summary of glucagon-like peptide-1 receptor agonist cardiovascular outcome trials

\begin{tabular}{|c|c|c|c|c|c|c|}
\hline Variable & ELIXA [63] & LEADER [65] & SUSTAIN-6 [66] & EXSCEL [64] & REWIND [68] & PIONEER-6 [67] \\
\hline No. of patients & 6,068 & 9,340 & 3,297 & 14,752 & 9,901 & 3,183 \\
\hline Drug & Lixisenatide & Liraglutide & Semaglutide & Exenatide & Dulaglutide & Semaglutide \\
\hline Dose & 10 or $20 \mu \mathrm{g}$ daily & $\begin{array}{l}1.8 \text { mg or max } \\
\text { tolerated dose per } \\
\text { day }\end{array}$ & $\begin{array}{c}0.5 \text { or } 1 \text { mg sq per } \\
\text { week }\end{array}$ & $2 \mathrm{mg}$ per week & 1.5 mg per week & $\begin{array}{l}14 \text { mg or max } \\
\text { tolerated dose per } \\
\text { day }\end{array}$ \\
\hline Main inclusion criteria & $\begin{array}{c}\text { T2DM+history } \\
\text { of ACS } \\
(<180 \text { days })\end{array}$ & $\begin{array}{c}\text { T2DM+CVD, } \\
\mathrm{CKD} \text {, or } \mathrm{HF} \text { at } \\
\geq 50 \mathrm{yr} \text { or } \mathrm{CV} \text { risk } \\
\text { at } \geq 60 \mathrm{yr}\end{array}$ & $\begin{array}{l}\text { T2DM+CVD, } \\
\mathrm{CKD} \text {, or } \mathrm{HF} \text { at } \\
\geq 50 \text { yr or } \mathrm{CV} \text { risk } \\
\text { at } \geq 60 \mathrm{yr}\end{array}$ & $\mathrm{T} 2 \mathrm{DM} \pm \mathrm{CVD}$ & $\begin{array}{l}\text { T2DM+prior } \\
\text { ACS or RF for } \\
\text { CVD }\end{array}$ & $\begin{array}{l}\text { T2DM+high } \\
\text { CVD risk }\end{array}$ \\
\hline Age, yr & 60.3 & 64.3 & 64.6 & 62 & 66.2 & 66.0 \\
\hline Female sex, \% & 30.7 & 35.7 & 39.3 & 38.0 & 46.3 & 31.6 \\
\hline HF patients, \% & 22.4 & 17.8 & 23.6 & 16.2 & 8.6 & 12.2 \\
\hline Median follow-up, yr & 2.1 & 3.8 & 2.1 & 3.2 & 5.4 & 1.3 \\
\hline Primary outcome & $\begin{array}{l}\text { 4-point MACE } \\
1.02(0.89-1.17)\end{array}$ & $\begin{array}{l}\text { 3-point } \mathrm{MACE}^{\mathrm{b}} \\
0.87(0.78-0.97)\end{array}$ & $\begin{array}{l}\text { 3-point MACE } \\
0.74(0.58-0.95)\end{array}$ & $\begin{array}{l}\text { 3-point } \mathrm{MACE}^{\mathrm{b}} \\
0.91(0.83-1.00)\end{array}$ & $\begin{array}{l}\text { 3-point MACE } \\
0.88(0.79-0.99)\end{array}$ & $\begin{array}{l}\text { 3-point MACE } \\
0.79(0.57-1.11)\end{array}$ \\
\hline HF hospitalization & $0.96(0.75-1.23)$ & $0.87(0.73-1.05)$ & $1.11(0.77-1.61)$ & $0.94(0.78-1.13)$ & $0.93(0.77-1.12)$ & $0.86(0.48-1.55)$ \\
\hline CV death & $0.98(0.78-1.22)$ & $0.78(0.66-0.93)$ & $0.90(0.65-1.48)$ & $0.88(0.76-1.02)$ & $0.91(0.78-1.06)$ & $0.49(0.27-0.92)$ \\
\hline All-cause mortality & $0.94(0.78-1.13)$ & $0.85(0.74-0.97)$ & $1.05(0.74-150)$ & $0.86(0.77-0.97)$ & $0.90(0.80-1.01)$ & $0.51(0.31-0.84)$ \\
\hline
\end{tabular}

Values are presented as hazard ratio (95\% confidence interval).

ELIXA, Evaluation of Lixisenatide in Acute Coronary Syndrome; LEADER, Liraglutide Effect and Action in Diabetes: Evaluation of Cardiovascular Outcome Results; SUSTAIN-6, Semaglutide and Cardiovascular outcomes in Patients with Type 2 Diabetes; EXSCEL, Exenatide Study of Cardiovascular Event Lowering; REWIND, Researching Cardiovascular Events with A Weekly Incretin in Diabetes; PIONEER-6, Peptide Innovation for Early Diabetes Treatment; T2DM, type 2 diabetes mellitus; ACS, acute coronary syndrome; CVD, cardiovascular disease; CKD, chronic kidney disease; HF, heart failure; RF, risk factor; CV, cardiovascular; MACE, major adverse cardiovascular event.

${ }^{\mathrm{a}}$ Composite outcome of cardiovascular death, nonfatal myocardial infarction, nonfatal stroke, or hospitalization for unstable angina, ${ }^{\mathrm{b} C o m p o s-}$ ite outcome of cardiovascular death, nonfatal myocardial infarction, or nonfatal stroke. 
peripheral glucose uptake and utilization [40]. The advantages of metformin include affordability, associated weight reduction, improved endothelial function, and low risk of hypoglycemia. Although metformin was previously contraindicated in HF due to concerns of lactic acidosis, several studies have shown a survival benefit [41-43]. A retrospective cohort study, using Taiwan's National Health Insurance database, compared HF hospitalization rates among 41,909 people with T2DM treated with metformin against propensity matched peers that had never received the drug [44]. Metformin use was associated with a reduced adjusted risk of HF hospitalization (aHR, $0.57 ; 95 \% \mathrm{CI}, 0.53$ to 0.62 ) and all-cause mortality (aHR, 0.67; 95\% CI, 0.60 to 0.75 ) [44]. A meta-analysis of nine cohort studies including 34,504 patients with DM and HF, metformin was associated with $20 \%$ reduction in all-cause mortality compared to control (mostly sulfonylurea therapy) (aOR, 0.80; 95\% CI, 0.73 to 0.88 ) [45]. Importantly, in patients with HFrEF (left ventricular ejection fraction $[\mathrm{LVEF}]<40 \%$ ), metformin was not associated with an increased risk of mortality or lactic aci- dosis [45]. Metformin is generally safe to use in patients with HF and T2DM but should be discontinued in patients who present with acute decompensated HF or have estimated glomerular filtration rate (eGFR) $<30 \mathrm{~mL} / \mathrm{min} / 1.73 \mathrm{~m}^{2}$.

\section{Sulfonylureas}

Sulfonylureas decrease plasma glucose by stimulating insulin secretion from pancreatic $\beta$-cells [46]. To date there are limited studies evaluating the safety and efficacy of sulfonylureas in patients with T2DM and HF. The United Kingdom Prospective Diabetes Study (UKPDS) compared sulfonylureas or insulin to treatment with dietary intervention found no difference in HF events in 3,867 newly diagnosed subjects with diabetes [26]. The Bypass Angioplasty Revascularization Investigation 2 Diabetes (BARI-2D) trial found no difference between an insulinproviding (sulfonylurea or insulin) or an insulin-sensitizing (metformin or TZD) strategy in 2,368 patients with diabetes and coronary artery disease, of which 141 had a history of HF, at 5.3 years [47]. A retrospective cohort study using the UK

Table 4. Summary of dipeptidyl peptidase-IV inhibitor cardiovascular outcome trials

\begin{tabular}{|c|c|c|c|c|c|}
\hline Variable & SAVOR-TIMI [75] & EXAMINE [76] & TECOS [77] & CARMELINA [78] & CAROLINA [50] \\
\hline No. of patients & 16,492 & 5,380 & 14,671 & 6,979 & 6,042 \\
\hline Drug & Saxagliptin & Alogliptin & Sitagliptin & Linagliptin & Linagliptin \\
\hline Dose & 2.5 or $5 \mathrm{mg}$ daily & 12.5 or $25 \mathrm{mg}$ daily & 50 or $100 \mathrm{mg}$ daily & $5 \mathrm{mg}$ & $5 \mathrm{mg}$ \\
\hline Main inclusion criteria & $\begin{array}{l}\text { T2DM+history of } \\
\text { or risk factors for } \\
\text { CVD }\end{array}$ & $\begin{array}{l}\text { T2DM+ACS } \\
\text { within 15-90 days of } \\
\text { randomization }\end{array}$ & $\begin{array}{c}\text { T2DM+history of } \\
\text { CVD }\end{array}$ & $\begin{array}{c}\text { T2DM+high } \\
\text { CVD and renal risk }\end{array}$ & $\begin{array}{l}\text { T2DM+high } \\
\text { CVD risk }\end{array}$ \\
\hline Age, $\mathrm{yr}^{\mathrm{a}}$ & 65.1 & 61.0 & 65.4 & 65.8 & 64.0 \\
\hline Female sex, \% & 33.1 & 32.1 & 29.9 & 37.1 & 39.9 \\
\hline HF patients, $\%$ & 12.8 & 27.9 & 18.3 & 26.8 & 4.5 \\
\hline Median follow-up, yr & 2.1 & 1.5 & 3.0 & 2.2 & 6.3 \\
\hline Primary outcome & $\begin{array}{l}\text { 3-point MACE } \\
1.00(0.89-1.12)\end{array}$ & $\begin{array}{c}\text { 3-point MACE } \\
0.96(95 \% \text { UL } \leq 1.16)\end{array}$ & $\begin{array}{l}\text { 4-point MACE }{ }^{\mathrm{b}} \\
0.98(0.89-1.08)\end{array}$ & $\begin{array}{l}\text { 3-point } \mathrm{MACE}^{\mathrm{b}} \\
1.02(0.89-1.17)\end{array}$ & $\begin{array}{l}\text { 3-point MACE } \\
0.98(0.84-1.14)\end{array}$ \\
\hline Heart failure hospitalization & $1.27(1.07-1.51)$ & Not reported & $1.00(0.83-1.20)$ & $0.90(0.74-1.08)$ & $1.21(0.92-1.59)$ \\
\hline Cardiovascular death & $1.03(0.87-1.22)$ & $0.85(0.66-1.10)$ & $1.03(0.89-1.19)$ & $0.96(0.81-1.14)$ & $1.00(0.81-1.24)$ \\
\hline All-cause mortality & $1.11(0.96-1.27)$ & $0.88(0.71-1.09)$ & $1.01(0.90-1.14)$ & $0.98(0.84-1.13)$ & $0.91(0.78-1.06)$ \\
\hline
\end{tabular}

Values are presented as hazard ratio (95\% confidence interval).

SAVOR-TIMI, Saxagliptin Assessment of Vascular Outcomes Recorded in Patients with Diabetes Mellitus-Thrombolysis in Myocardial Infarction 53; EXAMINE, Examination of Cardiovascular Outcomes With Alogliptin Versus Standard of Care; TECOS, Trial Evaluating Cardiovascular Outcomes with Sitagliptin; CARMELINA, Cardiovascular and Renal Microvascular Outcome Study with Linagliptin in Patients with Type 2 Diabetes Mellitus; CAROLINA, Cardiovascular Outcome Study of Linagliptin versus Glimepiride in Patients with Type 2 Diabetes; T2DM, type 2 diabetes mellitus; CVD, cardiovascular disease; ACS, acute coronary syndrome; HF, heart failure; MACE, major adverse cardiovascular event; UL, upper limit of one-sided confidence interval.

${ }^{\mathrm{a}}$ Age was reported as means in all trials except EXAMINE, which reported median age, ${ }^{\mathrm{b}}$ Composite outcome of cardiovascular death, myocardial infarction, or ischemic stroke with addition of hospitalization for unstable angina in TECOS trial. 


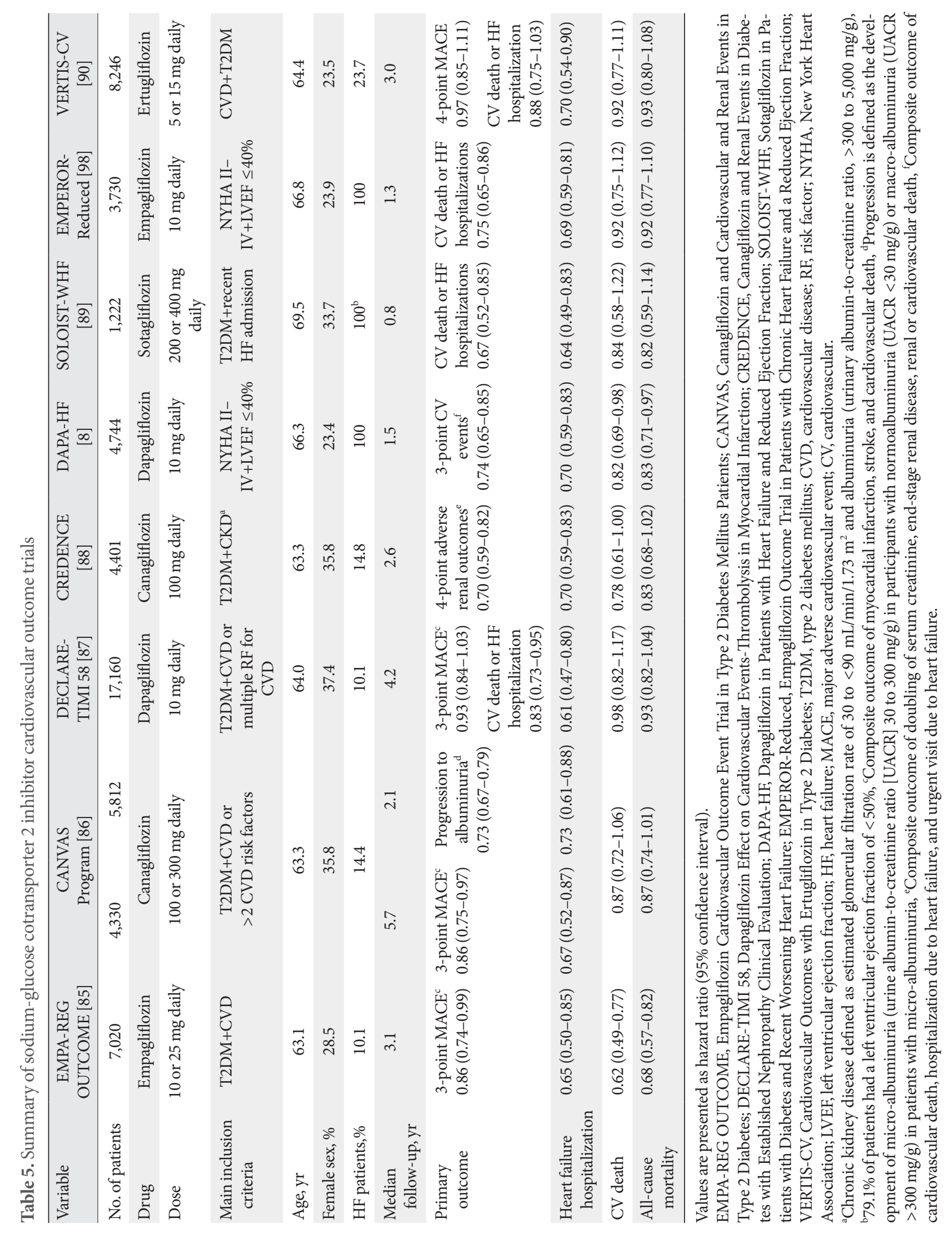


general practice research database of 91,521 patients with DM found that compared with metformin, monotherapy with firstor second-generation sulfonylureas was associated with a significant $24 \%$ to $61 \%$ increased risk for all-cause mortality $(P<0.001)$ and second-generation sulfonylureas with an $18 \%$ to $30 \%$ increased risk for $\operatorname{HF}(P=0.01$ and $P<0.001$, respectively) [48]. A retrospective cohort study of 407,145 Veterans Health Administration patients who were initiated on metformin or sulfonylureas found that sulfonylureas were associated with an increased risk of HF hospitalization (aHR, 1.30; 95\% CI, 1.20 to 1.42) [49]. Finally, the Cardiovascular Outcome Study of Linagliptin versus Glimepiride in Patients with Type 2 Diabetes (CAROLINA) trial found no difference in major adverse $\mathrm{CV}$ events or HF hospitalizations in 6,033 patients randomized to either linagliptin (DPP-IV inhibitor) or glimepiride (sulfonylurea) [50]. Sulfonylureas increase the risk of hypoglycemia and may increase HF risk in patients with T2DM. Although clinical data is limited, alternative agents with well-established safety profiles may be preferable in patients at high risk for or with established HF.

\section{Insulin}

Insulin has paracrine effects and can alter the metabolic milieu of cardiomyocytes resulting in maladaptive remodeling and myocardial dysfunction [51]. Observational studies have suggested greater CV mortality and increased HF prevalence in insulin treated patients with T2DM [52]. Few trials have prospectively evaluated the relationship between insulin treatment and HF outcomes. Such studies are challenging because insulin therapy is typically recommended in addition to other medications or when oral medications fail, both of which are potential confounders to clinical outcomes. A retrospective meta-analysis of 24,012 patients found that insulin was associated with a higher risk of all-cause mortality (OR, 2.02; 95\% CI, 1.87 to 2.19) and hospitalization for HF (OR, 1.42; 95\% CI, 1.32 to 1.53) [53]. The Outcome Reduction with Initial Glargine Intervention (ORIGIN) trial which randomized 12,537 patients with $\mathrm{DM}$, impaired glucose tolerance, or impaired fasting glucose to either insulin glargine or therapy without insulin reported a neutral effect on both initial and recurrent HF hospitalizations during a median follow-up of 6.2 years [54]. These findings raise the possibility that previously reported observational studies linking insulin use to HF may have confounded insulin use with other factors linked to poor prognosis (i.e., advanced age, difficult to control T2DM, chronic kidney disease [CKD]).
While these results are reassuring as they suggest insulin usage is not irrevocably linked to adverse CV outcomes in patients with HF, additional research is needed to inform guidelines on glucose management in high-risk patients with HF.

\section{Thiazolidinediones}

TZDs bind to and activate the nuclear receptor known as peroxisome proliferator activated receptor-alpha, which is responsible for regulating the expression of several metabolic genes. They stimulate insulin sensitivity through increased insulindependent glucose disposal and reduced hepatic glucose output [55]. Both rosiglitazone and pioglitazone are associated with reduced blood pressure, increased fluid retention, and increased risk of HF [56-58]. In the Efficacy of Pioglitazone on Macrovascular Outcomes in Patient with Type 2 Diabetes (PROACTIVE) trial, 5,238 patients with DM and macrovascular disease were randomized to receive pioglitazone or placebo and followed for a mean of 2 years [59]. Pioglitazone resulted in a $16 \%$ risk reduction in the secondary endpoint of all-cause mortality, nonfatal myocardial infarction (MI), and stroke (HR, 0.84 ; $95 \%$ CI, 0.72 to 0.98 ). However, compared to placebo pioglitazone was associated with an increased risk of HF (HR, 1.41; 95\% CI, 1.10 to 1.80) [56]. The Rosiglitazone Evaluated for Cardiac Outcomes and Regulation of Glycaemia in Diabetes (RECORD) trial found an increased risk of HF death or hospitalization associated with rosiglitazone (HR, 2.10; 95\% CI, 1.35 to 3.27) [60]. Several large meta-analyses have demonstrated an increased risk of HF and CV mortality with rosiglitazone use $[28-30,58]$. Due to increased sodium reabsorption, fluid retention, and increased risk for HF exacerbations, use of TZDs as a class is contraindicated in patients with New York Heart Association (NYHA) class III-IV HF [31,39].

\section{Glucagon-like peptide-1 receptor agonists}

GLP-1 is a peptide hormone released from the distal ileum and colon after oral nutrient consumption. Following administration of GLP-1 receptor agonists, elevated concentrations of GLP-1 reduce glucose by increasing glucose-dependent insulin secretion, decreasing glucagon secretion, and inducing satiety by delaying gastric emptying [61]. Beneficial secondary effects of decreased appetite include weight loss and improved lipid levels [62]. There are currently six U.S. Food and Drug Administration (FDA)-approved GLP-1 receptor agonists-albiglutide, dulaglutide, exenatide, liraglutide, lixisenatide, and semaglutide-for the treatment of T2DM. They are typically ad- 
ministered as a subcutaneous injection daily or weekly and can be given alone or in combination with other glucose-lowering agents.

In large randomized controlled trials GLP-1 receptor agonists have had mixed effects, generally demonstrating CV benefits in patients with T2DM but no apparent impact on HF hospitalizations (Table 3). In the Evaluation of Lixisenatide in Acute Coronary Syndrome (ELIXA) trial, lixisenatide did not significantly reduce major adverse $\mathrm{CV}$ events in patients with recent history of acute coronary syndrome or unstable angina at a median of 5 years (HR, 1.02; 95\% CI, 0.89 to 1.17) [63]. Similarly, the Exenatide Study of Cardiovascular Event Lowering (EXSCEL) trial, weekly exenatide did not reduce CV events or mortality compared to placebo [64]. However, in the Liraglutide Effect and Action in Diabetes: Evaluation of Cardiovascular Outcome Results (LEADER) trial, liraglutide resulted in a 13\% risk reduction in CV death, MI, or stroke [65]. In Semaglutide and Cardiovascular outcomes in Patients with Type 2 Diabetes (SUSTAIN-6), weekly semaglutide resulted in a $24 \%$ reduction in major adverse $\mathrm{CV}$ events along with a 39\% reduction in the incidence of nonfatal stroke [66]. In the Researching Cardiovascular Events with A Weekly Incretin in Diabetes (REWIND) trial, weekly dulaglutide resulted in a $12 \%$ reduction in CV events [67]. In the only oral GLP-1 receptor agonist trial, Peptide Innovation for Early Diabetes Treatment (PIONEER-6), max tolerated oral semaglutide was not inferior to placebo at reducing CV events [68]. The baseline prevalence of $\mathrm{HF}$ in these studies were relatively low, ranging from $8.6 \%$ in REWIND to $23.6 \%$ in SUSTAIN-6. Finally, in a large metaanalysis of 111,029 patients, treatment with GLP-1 receptor agonists was not associated with an increased risk of HF (OR, $0.62 ; 95 \%$ CI, 0.31 to 1.22 ) [69].

Although GLP-1 receptor agonists appear to improve cardiac function in animal studies of HF, improvements seen in preclinical trials have not translated into improved CV outcomes in clinical trials [70]. The Functional Impact of GLP-1 for Heart Failure Treatment (FIGHT) trial randomized 300 patients with HFrEF to receive liraglutide or placebo [71]. After 6 months, when compared to placebo liraglutide did not improve post-hospitalization clinical stability or HF readmissions in patients with advanced HF [71]. Finally, a small study of albiglutide in NYHA II-III patients found that albiglutide did not significantly improve LVEF, 6-minute walk test, or myocardial glucose and oxygen use, but did result in a modest improvement in peak oxygen consumption [71]. In the Effect of Liraglutide on Left Ventricular Function (LIVE) trial 241 patients with LVEF $\leq 45 \%$ were randomized to liraglutide or placebo. After 24 weeks, there were no significant differences in LVEF [72]. Furthermore, treatment with liraglutide was associated with a significant increase in heart rate and serious adverse $\mathrm{CV}$ events [72].

The effects of GLP-1 receptor agonists are heterogenous and may reduce the risk of major adverse $\mathrm{CV}$ events and mortality in the general population of patients with T2DM. While they appear safe to use in patients with HFrEF they have not been shown to reduce HF hospitalizations. There are no data to guide their use in patients with HFpEF.

\section{Dipeptidyl peptidase-IV inhibitors}

DPP-4 is an enzyme that inactivates GLP-1, which is responsible for insulin stimulation, suppression of glucagon, and delayed gastric emptying (as previously mentioned) [73]. DPP-4 inhibitors inhibit the degradation of GLP-1, therefore effectively improving effects of insulin and insulin sensitivity. DPP4 inhibition is also thought to mediate beneficial CV effects independent of GLP-1 by inducing endothelial nitric oxide synthase and regulating inflammation [74]. There are currently four FDA-approved DPP-4 inhibitors available for the treatment of T2DM-saxagliptin, alogliptin, sitagliptin, and linagliptin. These drugs do not lead to weight gain, are not associated with hypoglycemia, and can be administered in patients with renal insufficiency. Although DPP-4 inhibitors have not been shown to have a significant effect on CV events, results have been heterogenous and an increased risk of HF hospitalization was found with saxagliptin [75].

The CV safety of DDP-4 inhibitors has been demonstrated in several large clinical trials (Table 4). The Saxagliptin Assessment of Vascular Outcomes Recorded in Patients with Diabetes Mellitus-Thrombolysis in Myocardial Infarction 53 (SAVOR-TIMI 53) trial found no difference in CV events in patients treated with saxagliptin versus placebo; however, there was a $27 \%$ relative risk increase in HF hospitalization [75]. Similarly, the Examination of Cardiovascular Outcomes With Alogliptin Versus Standard of Care (EXAMINE) trial, found similar rates of $\mathrm{CV}$ events and a trend towards increased rates of HF hospitalizations (106 vs. $89, P=0.22$ ) in patients treated with alogliptin compared with placebo [76]. The Trial Evaluating Cardiovascular Outcomes with Sitagliptin (TECOS) study demonstrated no effect of sitagliptin on CV events or HF hospitalizations [77]. Similarly, the Cardiovascular and Renal Mi- 
crovascular Outcome Study with Linagliptin in Patients with Type 2 Diabetes Mellitus (CARMELINA) trial demonstrated no difference in $\mathrm{CV}$ outcomes and, importantly, no increased risk of HF hospitalizations in secondary analysis [78]. While the CAROLINA study had a relatively low prevalence of $\mathrm{HF}$ (4.5\%) it did not find a significant difference on major adverse $\mathrm{CV}$ events or HF hospitalizations in patients treated with linagliptin compared to glimepiride over a median follow up of 6.3 years [50].

Mechanisms for the possible deleterious effect of DDP-IV inhibitors on HF events remain uncertain. One that has been proposed is potentiation of stromal cell-derived factor 1 (SDF1) and indirect activation of the sympathetic nervous system and stimulation of $\beta$-adrenergic receptors resulting in cardiomyocyte apoptosis [79]. The first meta-analyses were dominated by the large contribution of the single large SAVOR-TIMI 53 trial [80]. Subsequent trials have not demonstrated an increased HF risk and recent meta-analyses have demonstrated no statistically significant increase in HF risk compared with placebo [81]. Currently, there is no evidence that DPP-IV inhibitors provide a CV benefit in patients with T2DM. In patients with high $\mathrm{CV}$ risk, saxagliptin may increase the risk for HF hospitalizations and should be avoided [75]. Overall, DPPIV inhibitors can be considered as third- or fourth-line agents in patients with HF and T2DM behind metformin, SGLT2 inhibitors, and GLP-1 receptor agonists.

\section{Sodium-glucose cotransporter 2 inhibitors}

The SGLT2 is a high-capacity, low-affinity transporter expressed almost exclusively in the initial convoluted portion of the proximal tubule of the nephron where it accounts for $90 \%$ of glucose reabsorption [82]. SGLT2 inhibition lowers the threshold of saturation, thereby increasing glucose secretion in the urine. Patients with T2DM express significantly higher numbers of SGLTs in the proximal tubule than do healthy individuals [83]. Consequently, glucose reabsorption from glomerular filtrate is greatly increased in these patients. SGLT2 inhibitors lower the threshold for glucose excretion to $<200$ to $250 \mathrm{mg} / 100 \mathrm{~mL}$ in urine [84]. Since glucosuria diminishes significantly as blood glucose normalizes, the risk of hypoglycemia with SGLT2 inhibitors is low unless they are used concomitantly with insulin or insulin secretagogues [84]. Beyond effects on blood glucose, SGLT2 inhibitors have diuretic and natriuretic effects, impact weight loss, and lower systolic blood pressure [85]. There are currently four FDA approved SGLT2 inhibitors—canagliflozin, dapagliflozin, empagliflozin and ertugliflozin.

There have been several large clinical trials evaluating the CV outcomes of SGLT2 inhibitors (Table 5). The Empagliflozin Cardiovascular Outcome Event Trial in Type 2 Diabetes Mellitus Patients (EMPA-REG OUTCOME) trial randomized 7,020 patients with T2DM to empagliflozin or placebo daily [85]. After a median of 3.1 years, treatment with empagliflozin was associated with a $14 \%$ relative risk reduction in adverse CV events driven largely by a 35\% risk reduction in HF hospitalizations [85]. The CANVAS program, integrated data from two trials involving 10,142 patients with T2DM at high risk for cardiovascular disease (CVD) were randomized to canagliflozin or placebo [86]. After a median of 3.1 years, canagliflozin resulted in a significant $14 \%$ risk reduction in $\mathrm{CV}$ events (HR, 0.86; $95 \% \mathrm{CI}, 0.75$ to 0.97 ) and $33 \%$ risk reduction in HF hospitalizations (HR, 0.67, 95\% CI, 0.52 to 0.87) [86]. Dapagliflozin Effect on Cardiovascular Events-Thrombolysis in Myocardial Infarction (DECLARE-TIMI 58) randomized 17,160 patients who had or were at risk for CVD to dapagliflozin or placebo. After a median of 4.2 years, treatment with dapagliflozin did not result in a significant difference in major adverse $\mathrm{CV}$ events but did result in a $27 \%$ risk reduction $\mathrm{HF}$ hospitalization (HR, 0.73 ; 95\% CI, 0.61 to 0.88 ) [87]. The Canagliflozin and Renal Events in Diabetes with Established Nephropathy Clinical Evaluation (CREDENCE) trial randomized 4,401 patients with T2DM and CKD (eGFR 30 to $<90$ $\mathrm{mL} / \mathrm{min} / 1.73 \mathrm{~m}^{2}$ ) to canagliflozin or placebo [88] was stopped early after a prespecified interim analysis found a $20 \%$ reduced risk of adverse CV events (HR, 0.80; 95\% CI, 0.67 to 0.95 ), and a $30 \%$ reduced risk for HF hospitalization (HR, 0.70; 95\% CI, 0.47 to 0.80 ) with canagliflozin [88]. The effects of sotagliflozin (a drug that inhibits SGLT1 as well as SGLT2 activity) were assessed in 1,222 patients with T2DM who were recently hospitalized for worsening HF in the Sotagliflozin in Patients with Diabetes and Recent Worsening Heart Failure (SOLOISTWHF). Although the trial was stopped prematurely by the sponsor due to lack of funding, sotagliflozin was associated with a significant reduction in the composite end-point of $\mathrm{CV}$ death and HF hospitalization (HR, 0.67; 95\% CI, 0.52 to 0.85 ) [89]. Finally, the recently published Evaluation of Ertugliflozin Efficacy and Safety Cardiovascular Outcomes Trial (VERTUS$\mathrm{CV}$ ) randomized 8,246 patients with T2DM and CVD to receive ertugliflozin or placebo [90]. In secondary analysis, compared to placebo ertugliflozin significantly reduced the risk of 
first HF hospitalization (HR, 0.70; 95\% CI, 0.54 to 0.90 ) and the composite for total HF hospitalization and CV death (HR, 0.83 ; $95 \%$ CI, 0.72 to 0.96 ) [91].

A recent meta-analysis of three large clinical trials, including 34,322 patients (60.2\% with established CVD), found that SGLT2 inhibitors reduced major adverse CV events by $11 \%$ (HR, 0.89; 95\% CI, 0.83 to 0.96), and the risk of CV death or hospitalization for HF by $23 \%$ (HR, 0.77 ; $95 \%$ CI, 0.71 to 0.84 ) [92]. Real-world studies, such as Comparative Effectiveness of Cardiovascular Outcomes in New Users of SGLT2 Inhibitors (CVD-REAL) reported that SGLT2 inhibitors, versus other glucose-lowering drugs, result in a $39 \%$ risk reduction in $\mathrm{HF}$ hospitalization (HR, 0.61 ; $95 \% \mathrm{CI}, 0.51$ to 0.73 ) and $51 \%$ risk reduction in mortality (HR, $0.49 ; 95 \% \mathrm{CI}, 0.41$ to 0.57 ) [93]. Similarly, the Non-interventional Study on the Effectiveness and Safety of Empagliflozin Compared With DPP-4 Inhibitors in Patients With Type 2 Diabetes in the United States (EMPRISE) trial found that empagliflozin, compared to sitagliptin, significantly reduced HF hospitalizations (HR, 0.50; 95\% CI, 0.28 to 0.91 ) [94]. These results reinforce the CV benefits of SGLT2 inhibitors in practice-based settings.

SGLT2 inhibitors are the first class of glucose-lowering agents demonstrated to reduce the risk of HF hospitalization in patients with $\mathrm{T} 2 \mathrm{DM}$ and subsequent trials were designed to assess their effectiveness as a HF therapy, regardless of whether T2DM was present. In the Dapagliflozin in Patients with Heart Failure and Reduced Ejection Fraction (DAPA-HF) trial [8], 4,744 patients without or without T2DM with NYHA Class IIIV $\mathrm{HF}$ and ejection fraction $\leq 40 \%$ were randomized to receive dapagliflozin or placebo in addition to recommended HF therapy [8]. After a median of 1.5 years, treatment with dapagliflozin resulted in a $26 \%$ risk reduction in HF hospitalization or CV death (HR, $0.74 ; 95 \%$ CI, 0.65 to 0.85 ). Benefits of dapagliflozin were similar in patients with and without T2DM. The frequency of adverse events related to volume depletion, renal dysfunction, and hypoglycemia did not differ between treatment groups [8]. In the Empagliflozin Outcome Trial in Patients with Chronic Heart Failure and a Reduced Ejection Fraction (EMPEROR-Reduced), 3,730 symptomatic HFrEF patients were assigned to received either empagliflozin or placebo, in addition to standard therapy. During a median followup of 16 months, the primary outcome of CV death and HF hospitalization was reduced by $25 \%$ in the empagliflozin group (HR, $0.75 ; 95 \%$ CI, 0.65 to 0.86 ) and the effect of the SGLT2 inhibitor was present regardless of the presence or absence of
T2DM. A subsequent prespecified meta-analysis of the results from DAPA-HF and EMPEROR-Reduced in which the effects of SGLT2 inhibition on mortality were assessed showed that among 8,474 patients combined from trials, treatment with an SGLT2 inhibitor significantly reduced all-cause and CV mortality [95].

Impaired renal function is common in patients with $\mathrm{HF}$ and $32 \%$ have CKD as defined as eGFR $<60 \mathrm{~mL} / \mathrm{min} / 1.73 \mathrm{~m}^{2}$. When present, CKD or worsening renal function is associated with increased mortality [96]. Several studies have examined the effect of SGLT2 inhibitors on renal function. In the CREDENCE trial, treatment with canagliflozin was associated with a significant reduction in the primary composite outcome of development of end-stage kidney disease, doubling of serum creatinine level, or death from renal or CV causes (HR, 0.70; 95\% CI, 0.59 to 0.82 ) [88]. In the DAPA-HF trial, compared with placebo treatment with dapagliflozin reduced the rate of decline in eGFR between day 14 and $720\left(-2.87 \mathrm{~mL} / \mathrm{min} / 1.73 \mathrm{~m}^{2}\right.$ vs. $-1.09 \mathrm{~mL} / \mathrm{min} / 1.72 \mathrm{~m}^{2}, P<0.001$ ) [97]. Similarly, in the EMPEROR-Reduced trial, the rate of decline in eGFR over the duration study was slower in the empagliflozin group than in the placebo group $\left(-0.55 \mathrm{~mL} / \mathrm{min} / 1.73 \mathrm{~m}^{2} /\right.$ year vs. $-2.28 \mathrm{~mL} /$ $\mathrm{min} / 1.73 \mathrm{~m}^{2} /$ year; $95 \% \mathrm{CI}, 1.10$ to 2.37 ) [98].

The potential mechanisms by which SGLT2 inhibitors improve CV outcomes are undergoing investigation [99]. The early and significant reduction in HF hospitalizations produced by SGLT2 inhibitors suggest that the predominant mechanism may be related to their hemodynamic effects. SGLT2 inhibitors act in the proximal tubule to inhibit $\mathrm{Na}+$ reabsorption resulting in osmotic diuresis, leading to reduced ventricular filling pressure, and cardiac workload [100]. SGLT2 inhibitors may also improve CV function due to a shift in myocardial fuel energetics. Under normal physiological conditions, $70 \%$ cardiac energy is derived from mitochondrial oxidation of free fatty acids (FFAs) [101]. In T2DM, as a result of peripheral insulin resistance, FFA oxidation markedly increases resulting in oxidative stress and cardiac lipotoxicity [102]. SGLT2 inhibitors increase hepatic synthesis and decrease the urinary excretion of ketones producing a mild, but persistent, hyperketonemia [103]. Under these conditions, beta-hydroxybutyrate is freely taken up by the heart and kidney and oxidized in preference to FFAs and glucose, producing fuel more efficiently. As noted earlier, sotagliflozin is a combined SGLT1 and SGLT2 inhibitor. The SGLT1 is found in nephrons, heart, skeletal muscle and small intestine, where it is the pri- 
mary mediator for glucose reabsorption. Additional clinical benefits conferred by the addition of SGLT1 inhibition are uncertain at present, as head-to-head comparison between combined SGLT and SGLT2 inhibition alone have not been performed.

Large scale outcome studies assessing potential benefits of SGLT2 inhibitors in HF patients are currently underway. The Empagliflozin Outcome Trial in Patients with Chronic Heart Failure with Preserved Ejection Fraction (EMPEROR-PRESERVED) trial has been designed to evaluate the effects of empagliflozin versus placebo on clinical outcomes in patients with HFpEF and it includes patients with and without T2DM. In addition, the Dapagliflozin Effect on Symptoms and Biomarkers in Patients with Heart Failure (DEFINE-HF) and Dapagliflozin in Preserved Ejection Fraction Heart Failure (PRESERVED-HF), and Empagliflozin Impact on Hemodynamics in Patients with Heart Failure (EMBRACE-HF) trials will evaluate potential mechanisms of SGLT2 inhibition in patients with established HFrEF and HFpEF.

Overall, SGLT2 inhibitors have demonstrated consistent reductions in CV mortality and HF hospitalizations making them the therapeutic agent of choice in the treatment of T2DM in patients with established HF or at high risk for developing HF. Recent trial results indicating benefits of SGLT2 inhibitors, regardless of whether they have T2DM indicate an important role of these drugs in the management of patients with HFrEF. These benefits, however, should be balanced by their potential risks including hypotension, genital mycotic infections, as well as lower-limb amputation and fractures (seen with canagliflozin only). SGLT2 inhibitors are contraindicated in patients with eGFR $<30 \mathrm{~mL} / \mathrm{min} / \mathrm{m}^{2}$.

\section{CONCLUSIONS}

The relationship between hyperglycemia and CV outcomes in patients with diabetes and HF is complex. Data from CV outcomes trials have underscored that HF is a critical outcome in patients with diabetes and suggest that glucose-lowering medications may influence the risk of HF development and progression. The advent of novel antihyperglycemic agents that can significantly reduce morbidity and mortality due to HF has impacted management choices for patients with T2DM. In particular, the consistent reductions in CV mortality and HF hospitalizations with SGLT2 inhibitors suggest that they should be considered in all patients with T2DM with HF or at high risk for developing HF. Future challenges include whether the SGLT2 inhibitors can improve outcomes in patients with $\mathrm{HFpEF}$ and the identification of therapeutic strategies that not only achieve and maintain glycemic control, but also reverse or prevent complications of DM. Given the high prevalence of $\mathrm{HF}$ in $\mathrm{DM}$, there is a strong imperative for further therapeutic advances in these areas. The results of ongoing and future clinical trials designed to test the effects of currently available and novel antihyperglycemic agents in HF are eagerly anticipated.

\section{CONFLICTS OF INTEREST}

No potential conflict of interest relevant to this article was reported.

\section{ORCID}

Jia Shen https://orcid.org/0000-0001-8994-3969

Barry H. Greenberg https://orcid.org/0000-0002-6605-9385

\section{FUNDING}

None

\section{ACKNOWLEDGMENTS}

None

\section{REFERENCES}

1. Saeedi P, Petersohn I, Salpea P, Malanda B, Karuranga S, Unwin $\mathrm{N}$, et al. Global and regional diabetes prevalence estimates for 2019 and projections for 2030 and 2045: Results from the International Diabetes Federation Diabetes Atlas, 9th edition. Diabetes Res Clin Pract 2019;157:107843.

2. Ambrosy AP, Fonarow GC, Butler J, Chioncel O, Greene SJ, Vaduganathan $\mathrm{M}$, et al. The global health and economic burden of hospitalizations for heart failure: lessons learned from hospitalized heart failure registries. J Am Coll Cardiol 2014; 63:1123-33.

3. SOLVD Investigators, Yusuf S, Pitt B, Davis CE, Hood WB, Cohn JN. Effect of enalapril on survival in patients with reduced left ventricular ejection fractions and congestive heart failure. N Engl J Med 1991;325:293-302.

4. Zannad F, McMurray JJ, Krum H, van Veldhuisen DJ, Swed- 
berg K, Shi H, et al. Eplerenone in patients with systolic heart failure and mild symptoms. N Engl J Med 2011;364:11-21.

5. Lee JH, Lim NK, Cho MC, Park HY. Epidemiology of heart failure in Korea: present and future. Korean Circ J 2016;46: 658-64.

6. McMurray JJ, Packer M, Desai AS, Gong J, Lefkowitz MP, Rizkala AR, et al. Angiotensin-neprilysin inhibition versus enalapril in heart failure. N Engl J Med 2014;371:993-1004.

7. Granger CB, McMurray JJ, Yusuf S, Held P, Michelson EL, Olofsson B, et al. Effects of candesartan in patients with chronic heart failure and reduced left-ventricular systolic function intolerant to angiotensin-converting-enzyme inhibitors: the CHARM-Alternative trial. Lancet 2003;362:772-6.

8. McMurray JJ, Solomon SD, Inzucchi SE, Kober L, Kosiborod MN, Martinez FA, et al. Dapagliflozin in patients with heart failure and reduced ejection fraction. N Engl J Med 2019;381: 1995-2008.

9. From AM, Leibson CL, Bursi F, Redfield MM, Weston SA, Jacobsen SJ, et al. Diabetes in heart failure: prevalence and impact on outcome in the population. Am J Med 2006;119:5919.

10. Cleland JG, Swedberg K, Follath F, Komajda M, Cohen-Solal A, Aguilar JC, et al. The EuroHeart Failure survey programme: a survey on the quality of care among patients with heart failure in Europe. Part 1: patient characteristics and diagnosis. Eur Heart J 2003;24:442-63.

11. Davies M, Hobbs F, Davis R, Kenkre J, Roalfe AK, Hare R, et al. Prevalence of left-ventricular systolic dysfunction and heart failure in the Echocardiographic Heart of England Screening study: a population based study. Lancet 2001;358: 439-44.

12. Amato L, Paolisso G, Cacciatore F, Ferrara N, Ferrara P, Canonico $S$, et al. Congestive heart failure predicts the development of non-insulin-dependent diabetes mellitus in the elderly. The Osservatorio Geriatrico Regione Campania Group. Diabetes Metab 1997;23:213-8.

13. Shi C, Wang LJ, Hu DF, Li JP, Zhu TQ, Shan Y, et al. Prevalence, clinical characteristics and outcome in patients with chronic heart failure and diabetes. Chin Med J (Engl) 2010; 123:646-50.

14. Shiba N, Shimokawa H. Chronic heart failure in Japan: implications of the CHART studies. Vasc Health Risk Manag 2008; 4:103-13.

15. Hjalmarson A, Goldstein S, Fagerberg B, Wedel H, Waagstein F, Kjekshus J, et al. Effects of controlled-release metoprolol on total mortality, hospitalizations, and well-being in patients with heart failure: the Metoprolol CR/XL Randomized Intervention Trial in congestive heart failure (MERIT-HF). MERIT-HF Study Group. JAMA 2000;283:1295-302.

16. Swedberg K, Komajda M, Bohm M, Borer JS, Ford I, DubostBrama A, et al. Ivabradine and outcomes in chronic heart failure (SHIFT): a randomised placebo-controlled study. Lancet 2010;376:875-85.

17. Felker GM, Benza RL, Chandler AB, Leimberger JD, Cuffe MS, Califf RM, et al. Heart failure etiology and response to milrinone in decompensated heart failure: results from the OPTIME-CHF study. J Am Coll Cardiol 2003;41:997-1003.

18. Sarma S, Mentz RJ, Kwasny MJ, Fought AJ, Huffman M, Subacius $\mathrm{H}$, et al. Association between diabetes mellitus and postdischarge outcomes in patients hospitalized with heart failure: findings from the EVEREST trial. Eur J Heart Fail 2013;15: 194-202.

19. Greenberg BH, Abraham WT, Albert NM, Chiswell K, Clare $\mathrm{R}$, Stough WG, et al. Influence of diabetes on characteristics and outcomes in patients hospitalized with heart failure: a report from the Organized Program to Initiate Lifesaving Treatment in Hospitalized Patients with Heart Failure (OPTIMIZE-HF). Am Heart J 2007;154:277.

20. Allen LA, Magid DJ, Gurwitz JH, Smith DH, Goldberg RJ, Saczynski J, et al. Risk factors for adverse outcomes by left ventricular ejection fraction in a contemporary heart failure population. Circ Heart Fail 2013;6:635-46.

21. MacDonald MR, Petrie MC, Varyani F, Ostergren J, Michelson EL, Young JB, et al. Impact of diabetes on outcomes in patients with low and preserved ejection fraction heart failure: an analysis of the Candesartan in Heart failure: Assessment of Reduction in Mortality and morbidity (CHARM) programme. Eur Heart J 2008;29:1377-85.

22. Dauriz M, Targher G, Laroche C, Temporelli PL, Ferrari R, Anker S, et al. Association between diabetes and 1-year adverse clinical outcomes in a multinational cohort of ambulatory patients with chronic heart failure: results from the ESCHFA heart failure long-term registry. Diabetes Care 2017;40: 671-8.

23. Dauriz M, Mantovani A, Bonapace S, Verlato G, Zoppini G, Bonora E, et al. Prognostic impact of diabetes on long-term survival outcomes in patients with heart failure: a meta-analysis. Diabetes Care 2017;40:1597-605.

24. Stettler C, Allemann S, Juni P, Cull CA, Holman RR, Egger M, et al. Glycemic control and macrovascular disease in types 1 
and 2 diabetes mellitus: meta-analysis of randomized trials. Am Heart J 2006;152:27-38.

25. ADVANCE Collaborative Group, Patel A, MacMahon S, Chalmers J, Neal B, Billot L, et al. Intensive blood glucose control and vascular outcomes in patients with type 2 diabetes. $\mathrm{N}$ Engl J Med 2008;358:2560-72.

26. UK Prospective Diabetes Study (UKPDS) Group. Intensive blood-glucose control with sulphonylureas or insulin compared with conventional treatment and risk of complications in patients with type 2 diabetes (UKPDS 33). Lancet 1998;352: 837-53.

27. Ismail-Beigi F, Craven T, Banerji MA, Basile J, Calles J, Cohen $\mathrm{RM}$, et al. Effect of intensive treatment of hyperglycaemia on microvascular outcomes in type 2 diabetes: an analysis of the ACCORD randomised trial. Lancet 2010;376:419-30.

28. Singh S, Loke YK, Furberg CD. Long-term risk of cardiovascular events with rosiglitazone: a meta-analysis. JAMA 2007; 298:1189-95.

29. Mannucci E, Monami M, Di Bari M, Lamanna C, Gori F, Gensini GF, et al. Cardiac safety profile of rosiglitazone: a comprehensive meta-analysis of randomized clinical trials. Int J Cardiol 2010;143:135-40.

30. Graham DJ, Ouellet-Hellstrom R, MaCurdy TE, Ali F, Sholley C, Worrall C, et al. Risk of acute myocardial infarction, stroke, heart failure, and death in elderly medicare patients treated with rosiglitazone or pioglitazone. JAMA 2010;304:411-8.

31. Kaul S, Bolger AF, Herrington D, Giugliano RP, Eckel RH. Thiazolidinedione drugs and cardiovascular risks: a science advisory from the American Heart Association and American College of Cardiology Foundation. Circulation 2010;121: 1868-77.

32. Iribarren C, Karter AJ, Go AS, Ferrara A, Liu JY, Sidney S, et al. Glycemic control and heart failure among adult patients with diabetes. Circulation 2001;103:2668-73.

33. Aguilar D, Bozkurt B, Ramasubbu K, Deswal A. Relationship of hemoglobin $\mathrm{A} 1 \mathrm{C}$ and mortality in heart failure patients with diabetes. J Am Coll Cardiol 2009;54:422-8.

34. Eshaghian S, Horwich TB, Fonarow GC. An unexpected inverse relationship between $\mathrm{HbAlc}$ levels and mortality in patients with diabetes and advanced systolic heart failure. Am Heart J 2006;151:91.

35. Gerstein HC, Swedberg K, Carlsson J, McMurray JJ, Michelson EL, Olofsson B, et al. The hemoglobin Alc level as a progressive risk factor for cardiovascular death, hospitalization for heart failure, or death in patients with chronic heart fail- ure: an analysis of the Candesartan in Heart failure: Assessment of Reduction in Mortality and Morbidity (CHARM) program. Arch Intern Med 2008;168:1699-704.

36. Elder DH, Singh JS, Levin D, Donnelly LA, Choy AM, George J, et al. Mean HbA1c and mortality in diabetic individuals with heart failure: a population cohort study. Eur J Heart Fail 2016;18:94-102.

37.Castagno D, Baird-Gunning J, Jhund PS, Biondi-Zoccai G, MacDonald MR, Petrie MC, et al. Intensive glycemic control has no impact on the risk of heart failure in type 2 diabetic patients: evidence from a 37,229 patient meta-analysis. Am Heart J 2011;162:938-48.

38. American Diabetes Association. 6. Glycemic targets: standards of medical care in diabetes-2020. Diabetes Care 2020;43(Suppl 1):S66-S76.

39. American Diabetes Association. 9. Pharmacologic approaches to glycemic treatment: standards of medical care in diabetes-2020. Diabetes Care 2020;43(Suppl 1):S98-S110.

40. Gong L, Goswami S, Giacomini KM, Altman RB, Klein TE. Metformin pathways: pharmacokinetics and pharmacodynamics. Pharmacogenet Genomics 2012;22:820-7.

41. UK Prospective Diabetes Study (UKPDS) Group. Effect of intensive blood-glucose control with metformin on complications in overweight patients with type 2 diabetes (UKPDS 34). Lancet 1998;352:854-65.

42. Eurich DT, Majumdar SR, McAlister FA, Tsuyuki RT, Johnson JA. Improved clinical outcomes associated with metformin in patients with diabetes and heart failure. Diabetes Care 2005; 28:2345-51.

43. Romero SP, Andrey JL, Garcia-Egido A, Escobar MA, Perez V, Corzo R, et al. Metformin therapy and prognosis of patients with heart failure and new-onset diabetes mellitus: a propensity-matched study in the community. Int J Cardiol 2013;166: 404-12.

44. Tseng $\mathrm{CH}$. Metformin use is associated with a lower risk of hospitalization for heart failure in patients with type 2 diabetes mellitus: a retrospective cohort analysis. J Am Heart Assoc 2019;8:e011640.

45. Eurich DT, Weir DL, Majumdar SR, Tsuyuki RT, Johnson JA, Tjosvold L, et al. Comparative safety and effectiveness of metformin in patients with diabetes mellitus and heart failure: systematic review of observational studies involving 34,000 patients. Circ Heart Fail 2013;6:395-402.

46. Proks P, Reimann F, Green N, Gribble F, Ashcroft F. Sulfonylurea stimulation of insulin secretion. Diabetes 2002;51 (Suppl 
3):S368-76.

47. BARI 2D Study Group, Frye RL, August P, Brooks MM, Hardison RM, Kelsey SF, et al. A randomized trial of therapies for type 2 diabetes and coronary artery disease. $\mathrm{N}$ Engl J Med 2009;360:2503-15.

48. Tzoulaki I, Molokhia M, Curcin V, Little MP, Millett CJ, Ng A, et al. Risk of cardiovascular disease and all cause mortality among patients with type 2 diabetes prescribed oral antidiabetes drugs: retrospective cohort study using UK general practice research database. BMJ 2009;339:b4731.

49. Roumie CL, Min JY, D’Agostino McGowan L, Presley C, Grijalva CG, Hackstadt AJ, et al. Comparative safety of sulfonylurea and metformin monotherapy on the risk of heart failure: a cohort study. J Am Heart Assoc 2017;6:e005379.

50. Rosenstock J, Kahn SE, Johansen OE, Zinman B, Espeland MA, Woerle HJ, et al. Effect of linagliptin vs glimepiride on major adverse cardiovascular outcomes in patients with type 2 diabetes: the CAROLINA randomized clinical trial. JAMA 2019;322:1155-66.

51. Riehle C, Abel ED. Insulin signaling and heart failure. Circ Res 2016;118:1151-69.

52. Cooper LB, Mi X, Mentz RJ, Green JB, Anstrom KJ, Hernan$\operatorname{dez}$ AF, et al. Management of newly treated diabetes in Medicare beneficiaries with and without heart failure. Clin Cardiol 2017;40:38-45.

53. Cosmi F, Shen L, Magnoli M, Abraham WT, Anand IS, Cleland JG, et al. Treatment with insulin is associated with worse outcome in patients with chronic heart failure and diabetes. Eur J Heart Fail 2018;20:888-95.

54. Gerstein HC, Jung H, Ryden L, Diaz R, Gilbert RE, Yusuf S, et al. Effect of basal insulin glargine on first and recurrent episodes of heart failure hospitalization: the ORIGIN trial (Outcome Reduction with Initial Glargine Intervention). Circulation 2018;137:88-90.

55. Della-Morte D, Palmirotta R, Rehni AK, Pastore D, Capuani B, Pacifici F, et al. Pharmacogenomics and pharmacogenetics of thiazolidinediones: role in diabetes and cardiovascular risk factors. Pharmacogenomics 2014;15:2063-82.

56. Erdmann E, Charbonnel B, Wilcox RG, Skene AM, MassiBenedetti M, Yates J, et al. Pioglitazone use and heart failure in patients with type 2 diabetes and preexisting cardiovascular disease: data from the PROactive study (PROactive 08). Diabetes Care 2007;30:2773-8.

57. Nissen SE, Wolski K. Effect of rosiglitazone on the risk of myocardial infarction and death from cardiovascular causes. $\mathrm{N}$
Engl J Med 2007;356:2457-71.

58. Wallach JD, Wang K, Zhang AD, Cheng D, Grossetta Nardini $\mathrm{HK}$, Lin $\mathrm{H}$, et al. Updating insights into rosiglitazone and cardiovascular risk through shared data: individual patient and summary level meta-analyses. BMJ 2020;368:17078.

59. Dormandy JA, Charbonnel B, Eckland DJ, Erdmann E, MassiBenedetti M, Moules IK, et al. Secondary prevention of macrovascular events in patients with type 2 diabetes in the PROactive Study (PROspective pioglitAzone Clinical Trial In macroVascular Events): a randomized controlled trial. Lancet 2005;366:1279-89.

60. Komajda M, McMurray JJ, Beck-Nielsen H, Gomis R, Hanefeld M, Pocock SJ, et al. Heart failure events with rosiglitazone in type 2 diabetes: data from the RECORD clinical trial. Eur Heart J 2010;31:824-31.

61. Drucker DJ, Nauck MA. The incretin system: glucagon-like peptide- 1 receptor agonists and dipeptidyl peptidase- 4 inhibitors in type 2 diabetes. Lancet 2006;368:1696-705.

62. Trujillo JM, Nuffer W, Ellis SL. GLP-1 receptor agonists: a review of head-to-head clinical studies. Ther Adv Endocrinol Metab 2015;6:19-28.

63. Pfeffer MA, Claggett B, Diaz R, Dickstein K, Gerstein HC, Kober LV, et al. Lixisenatide in patients with type 2 diabetes and acute coronary syndrome. N Engl J Med 2015;373:2247-57.

64. Holman RR, Bethel MA, Mentz RJ, Thompson VP, Lokhnygina Y, Buse JB, et al. Effects of once-weekly exenatide on cardiovascular outcomes in type 2 diabetes. N Engl J Med 2017; 377:1228-39.

65. Marso SP, Daniels GH, Brown-Frandsen K, Kristensen P, Mann JF, Nauck MA, et al. Liraglutide and cardiovascular outcomes in type 2 diabetes. N Engl J Med 2016;375:311-22.

66. Marso SP, Bain SC, Consoli A, Eliaschewitz FG, Jodar E, Leiter LA, et al. Semaglutide and cardiovascular outcomes in patients with type 2 diabetes. N Engl J Med 2016;375:1834-44.

67. Gerstein HC, Colhoun HM, Dagenais GR, Diaz R, Lakshmanan M, Pais P, et al. Dulaglutide and cardiovascular outcomes in type 2 diabetes (REWIND): a double-blind, randomized placebo-controlled trial. Lancet 2019;394:121-30.

68. Husain M, Birkenfeld AL, Donsmark M, Dungan K, Eliaschewitz FG, Franco DR, et al. Oral semaglutide and cardiovascular outcomes in patients with type 2 diabetes. $\mathrm{N}$ Engl J Med 2019;381:841-51.

69. Li L, Li S, Liu J, Deng K, Busse JW, Vandvik PO, et al. Glucagon-like peptide-1 receptor agonists and heart failure in type 2 diabetes: systematic review and meta-analysis of random- 
ized and observational studies. BMC Cardiovasc Disord 2016; 16:91.

70. Munaf M, Pellicori P, Allgar V, Wong K. A meta-analysis of the therapeutic effects of glucagon-like peptide- 1 agonist in heart failure. Int J Pept 2012;2012:249827.

71. Margulies KB, Hernandez AF, Redfield MM, Givertz MM, Oliveira GH, Cole R, et al. Effects of liraglutide on clinical stability among patients with advanced heart failure and reduced ejection fraction: a randomized clinical trial. JAMA 2016;316: 500-8.

72. Jorsal A, Kistorp C, Holmager P, Tougaard RS, Nielsen R, Hanselmann A, et al. Effect of liraglutide, a glucagon-like peptide- 1 analogue, on left ventricular function in stable chronic heart failure patients with and without diabetes (LIVE)-a multicentre, double-blind, randomised, placebo-controlled trial. Eur J Heart Fail 2017;19:69-77.

73. Thornberry NA, Gallwitz B. Mechanism of action of inhibitors of dipeptidyl-peptidase-4 (DPP-4). Best Pract Res Clin Endocrinol Metab 2009;23:479-86.

74. Widlansky ME, Puppala VK, Suboc TM, Malik M, Branum A, Signorelli K, et al. Impact of DPP-4 inhibition on acute and chronic endothelial function in humans with type 2 diabetes on background metformin therapy. Vasc Med 2017;22:18996.

75. Scirica BM, Bhatt DL, Braunwald E, Steg PG, Davidson J, Hirshberg B, et al. Saxagliptin and cardiovascular outcomes in patients with type 2 diabetes mellitus. N Engl J Med 2013;369: $1317-26$

76. White WB, Cannon CP, Heller SR, Nissen SE, Bergenstal RM, Bakris GL, et al. Alogliptin after acute coronary syndrome in patients with type 2 diabetes. N Engl J Med 2013;369:1327-35.

77. Green JB, Bethel MA, Armstrong PW, Buse JB, Engel SS, Garg J, et al. Effect of sitagliptin on cardiovascular outcomes in type 2 diabetes. N Engl J Med 2015;373:232-42.

78. Rosenstock J, Perkovic V, Johansen OE, Cooper ME, Kahn SE, Marx N, et al. Effect of linagliptin vs placebo on major cardiovascular events in adults with type 2 diabetes and high cardiovascular and renal risk: the CARMELINA randomized clinical trial. JAMA 2019;321:69-79.

79. Packer M. Do DPP-4 inhibitors cause heart failure events by promoting adrenergically mediated cardiotoxicity?: clues from laboratory models and clinical trials. Circ Res 2018;122: 928-32.

80. Li L, Li S, Deng K, Liu J, Vandvik PO, Zhao P, et al. Dipeptidyl peptidase- 4 inhibitors and risk of heart failure in type 2 diabe- tes: systematic review and meta-analysis of randomised and observational studies. BMJ 2016;352:i610.

81. Zheng SL, Roddick AJ, Aghar-Jaffar R, Shun-Shin MJ, Francis $\mathrm{D}$, Oliver $\mathrm{N}$, et al. Association between use of sodium-glucose cotransporter 2 inhibitors, glucagon-like peptide 1 agonists, and dipeptidyl peptidase 4 inhibitors with all-cause mortality in patients with type 2 diabetes: a systematic review and metaanalysis. JAMA 2018;319:1580-91.

82. Kalra S. Sodium glucose co-transporter-2 (SGLT2) inhibitors: a review of their basic and clinical pharmacology. Diabetes Ther 2014;5:355-66.

83. Ferrannini E, Solini A. SGLT2 inhibition in diabetes mellitus: rationale and clinical prospects. Nat Rev Endocrinol 2012;8: 495-502.

84. Chao EC. SGLT-2 inhibitors: a new mechanism for glycemic control. Clin Diabetes 2014;32:4-11.

85. Zinman B, Wanner C, Lachin JM, Fitchett D, Bluhmki E, Hantel S, et al. Empagliflozin, cardiovascular outcomes, and mortality in type 2 diabetes. N Engl J Med 2015;373:2117-28.

86. Neal B, Perkovic V, Mahaffey KW, de Zeeuw D, Fulcher G, Erondu N, et al. Canagliflozin and cardiovascular and renal events in type 2 diabetes. N Engl J Med 2017;377:644-57.

87. Wiviott SD, Raz I, Bonaca MP, Mosenzon O, Kato ET, Cahn A, et al. Dapagliflozin and cardiovascular outcomes in type 2 diabetes. N Engl J Med 2019;380:347-57.

88. Perkovic V, Jardine MJ, Neal B, Bompoint S, Heerspink HJL, Charytan DM, et al. Canagliflozin and renal outcomes in type 2 diabetes and nephropathy. N Engl J Med 2019;380:2295306.

89. Bhatt DL, Szarek M, Steg PG, Cannon CP, Leiter LA, McGuire DK, et al. Sotagliflozin in patients with diabetes and recent worsening heart failure. N Engl J Med 2021;384:117-28.

90. Cannon CP, Pratley R, Dagogo-Jack S, Mancuso J, Huyck S, Masiukiewicz U, et al. Cardiovascular outcomes with ertugliflozin in type 2 diabetes. N Engl J Med 2020;383:1425-35.

91. Cosentino F, Cannon CP, Cherney DZ, Masiukiewicz U, Pratley R, Dagogo-Jack S, et al. Efficacy of ertugliflozin on heart failure-related events in patients with type 2 diabetes mellitus and established atherosclerotic cardiovascular disease: results of the VERTIS CV trial. Circulation 2020;142:2205-15.

92. Zelniker TA, Wiviott SD, Raz I, Im K, Goodrich EL, Bonaca MP, et al. SGLT2 inhibitors for primary and secondary prevention of cardiovascular and renal outcomes in type 2 diabetes: a systematic review and meta-analysis of cardiovascular outcome trials. Lancet 2019;393:31-9. 
93. Kosiborod M, Cavender MA, Fu AZ, Wilding JP, Khunti K, Holl RW, et al. Lower risk of heart failure and death in patients initiated on sodium-glucose cotransporter-2 inhibitors versus other glucose-lowering drugs: the CVD-REAL study (Comparative Effectiveness of Cardiovascular Outcomes in New Users of Sodium-Glucose Cotransporter-2 Inhibitors). Circulation 2017;136:249-59.

94. Patorno E, Pawar A, Franklin JM, Najafzadeh M, Deruaz-Luyet A, Brodovicz KG, et al. Empagliflozin and the risk of heart failure hospitalization in routine clinical care. Circulation 2019;139:2822-30.

95. Zannad F, Ferreira JP, Pocock SJ, Anker SD, Butler J, Filippatos G, et al. SGLT2 inhibitors in patients with heart failure with reduced ejection fraction: a meta-analysis of the EMPERORreduced and DAPA-HF trials. Lancet 2020;396:819-29.

96. Damman K, Valente MA, Voors AA, O’Connor CM, van Veldhuisen DJ, Hillege HL. Renal impairment, worsening renal function, and outcome in patients with heart failure: an updated meta-analysis. Eur Heart J 2014;35:455-69.

97. Jhund PS, Solomon SD, Docherty KF, Heerspink HJ, Anand IS, Bohm M, et al. Efficacy of dapagliflozin on renal function and outcomes in patients with heart failure with reduced ejection fraction: results of DAPA-HF. Circulation 2021;143:298309.

98. Packer M, Anker SD, Butler J, Filippatos G, Pocock SJ, Carson $\mathrm{P}$, et al. Cardiovascular and renal outcomes with empagliflozin in heart failure. N Engl J Med 2020;383:1413-24.

99. Tamargo J. Sodium-glucose cotransporter 2 inhibitors in heart failure: potential mechanisms of action, adverse effects and future developments. Eur Cardiol 2019;14:23-32.

100. McMurray J. EMPA-REG: the "diuretic hypothesis". J Diabetes Complications 2016;30:3-4.

101. Lopaschuk GD, Ussher JR, Folmes CD, Jaswal JS, Stanley WC. Myocardial fatty acid metabolism in health and disease. Physiol Rev 2010;90:207-58.

102. Scheen AJ. Pharmacodynamics, efficacy and safety of sodiumglucose co-transporter type 2 (SGLT2) inhibitors for the treatment of type 2 diabetes mellitus. Drugs 2015;75:33-59.

103. Mudaliar S, Alloju S, Henry RR. Can a shift in fuel energetics explain the beneficial cardiorenal outcomes in the EMPAREG OUTCOME Study?: a unifying hypothesis. Diabetes Care 2016;39:1115-22. 